\title{
Ways to heat hot water via the heat pipes
}

\author{
Peter Hrabovský ${ }^{1,{ }^{*}, \text { Zuzana Kolková }{ }^{1}, \text { Jozef Matušov }}{ }^{1}$ and Patrik Nemec $^{2}$ \\ ${ }^{1}$ University of Zilina - Reasearch Centre, Univerzitná 8215/1, 01026 Zilina, Slovakia \\ ${ }^{2}$ University of Zilina - Department of Power Energy, Univerzitná 8215/1, 01026 Zilina, Slovakia
}

\begin{abstract}
The article deals various ways of heating hot water where heat is transferred by the basic phenomena of heat transfer theories, which take place on an innovative basis with the advantage of the absence of mechanical elements. The heat transfer in this case ensures a change in the phase-in phase of the working substance - the fluid - from which the thermal output and the efficiency of the device are derived. The devices described in this article work on the same principle of heat transfer. Each device is characterized by own construction and the principle of heat transfer. Heat pipes are classified according to the way of operation and the place of use. Subdivision of the heat pipe, in terms of its actual, use in the desired temperature range. At present, heating plants use cooling technologies (nuclear power, space stations, IT).
\end{abstract}

\section{Introduction}

Currently, the European Union's energy policy, as well as the Slovak Republic, pays great attention to the more efficient use of different forms of energy. Increasing emphasis is placed on energy self-sufficiency, increased efficiency of energy facilities and the use of renewable energy sources. Such a source of energy is also used in small heat sources, mostly to ensure thermal comfort in households.

The article describes various designs of heat pipes, which can be used in the heating of hot water by various methods. The basic distribution of heat transfer to the DHW cylinder is two ways - direct and indirect. The direct heat transfer method is defined by the direct contact of the heated substance with the heat transfer material. Indirect method of heat transfer is not directly in contact with the heated substance, but the heat is transferred through the heat transfer medium. The article describes hot water heating devices, collectively called heat pipes.

\section{Gravitational heat pipe}

Gravitational heat pipe is a device defined in the literature as a heat transfer device with a high thermal conductivity higher than the thermal conductivity of copper or other heat conductive materials used in thermal engineering [1, 2]. The Gravity Heat Pipe (GHP) works on the principle of phase change, from vapour to heat, and from steam to liquid when

\footnotetext{
*Corresponding author: peter.hrabovsky@,rc.uniza.sk
} 
the heat is transferred $[3,4]$. The functional GHP contains a predetermined amount of a working substance capable of group transfers, which is in liquid and gaseous form. GHP consists of 3 parts: evaporation, adiabatic and condensation [5]. With regard to the material and purpose of use, a working substance is selected for the optimal functioning of the GHP [6].
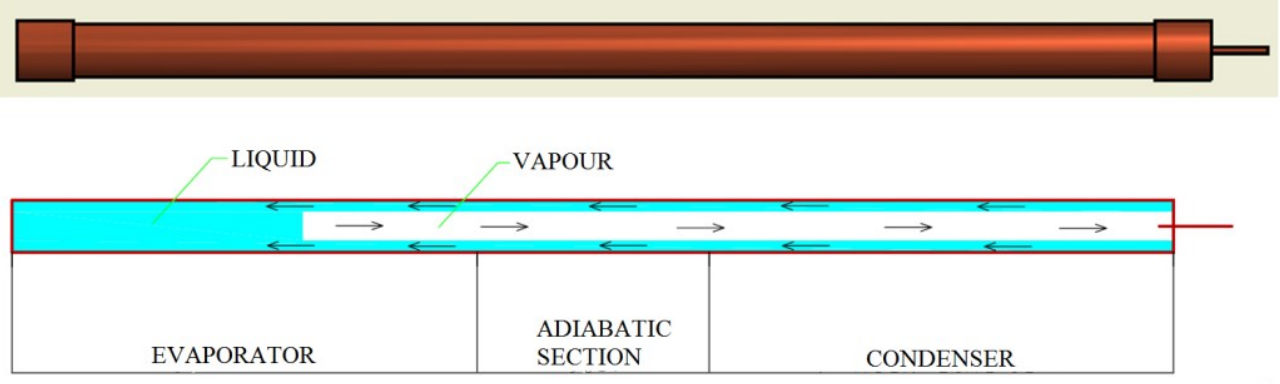

a

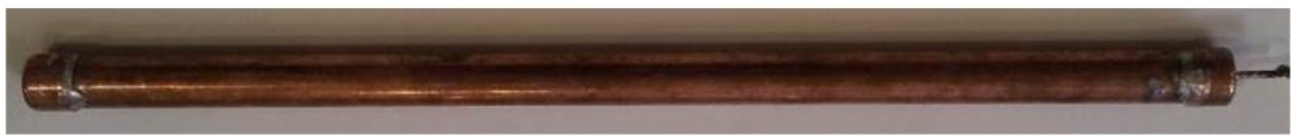

Fig. 1. Gravity heat pipe.

\section{Loop heat pipe}

The loop heat pipe works on the same principle as the gravity heat pipe. The circulation of the working substance occurs in the loop heat pipe. This type of heat pipe is used for longdistance applications where longer piping needs to be used. An important aspect of the operation of this heat pipe is the actual position of the individual components. As mentioned in the previous chapter (2), the heat pipe consists of the evaporation, condensation and transmission lines. In this type, the position of the evaporator and the condenser must be ensured from the construction point of view. The evaporator must always be under the condenser. Other aspects of the design of this type of heat pipe are based on the application in question, where the type of heat source and the place of consumption of heat energy are decided.

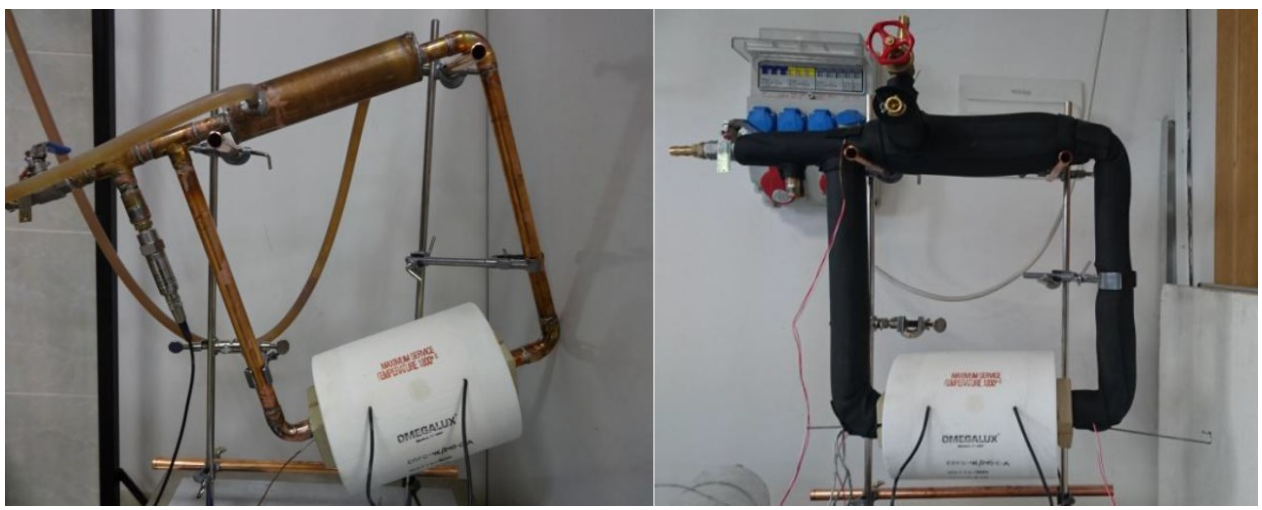

Fig. 2. Real state of loop heat pipe model.

The heat transfer media, respectively the working fluid of the loop heat pipe is distilled water. At the inlet and outlet sections of the loop heat pipe and heat exchanger, temperature 
sensors are located. At the top there is a pressure sensor and a valve that serves to fill and empty the volume of the loop heat pipe with the working fluid.

\section{Proposal of loop heat pipe for water heating}

In the design of the plant, requirements have been laid down for removing heat from combustion gases generated by the combustion process in a heat source. From the point of view of the construction and arrangement of the individual parts of the device, it is necessary to ensure the location of the evaporator part of the heat pipe in the heat source so that the combustion occurs with the surface of the evaporator.

Suggested variants show the possibility of removing heat from the flue gas. The first variant is structurally based on the removal of heat from the chimney section. In the chimney pipe, a vaporizer is located, which is a separate block with the possibility of assembly and dismantling from the chimney pipe.
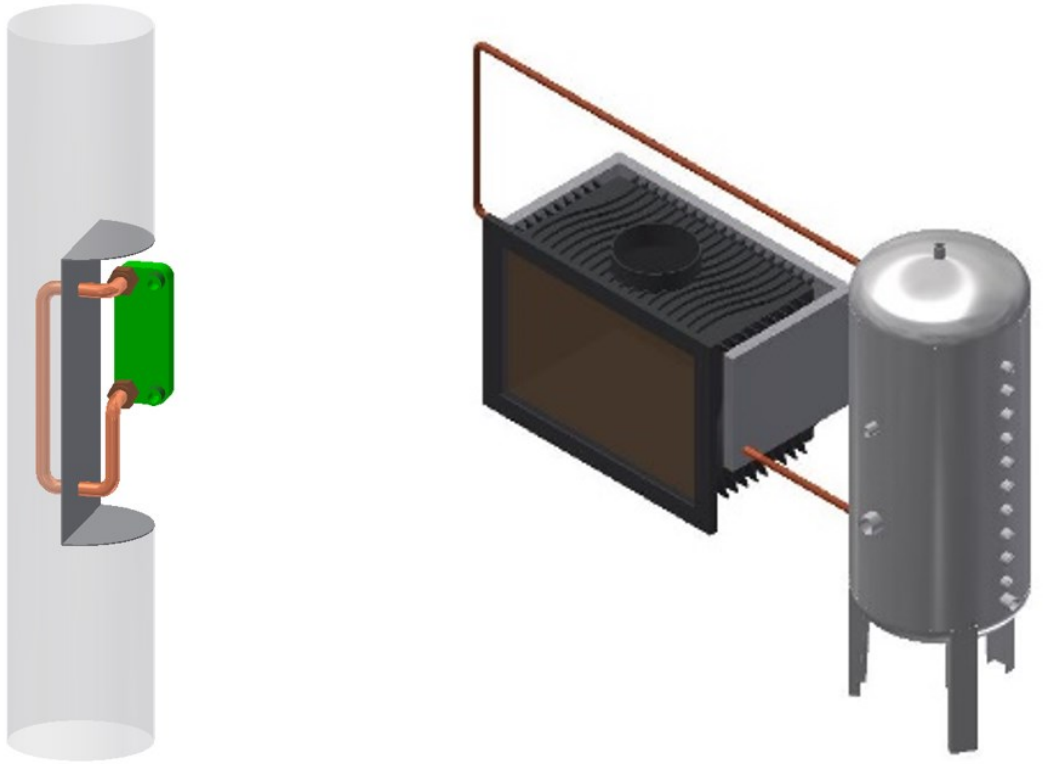

Fig. 3. Left variant evaporator with reflow exchanger, right variant with evaporator around combustion.

The second variant is based on heat removal by the evaporator, which is located on the outside of the combustion chamber shell. Its design consists of a block copying the shape of the combustion chamber.

A third variant is based on the removal of heat from the combustion gases directly in the combustion chamber. Its structure consists of a block located in the back of the heat source combustion chamber.

The second and third variants are connected to a heat exchanger in a storage tank of 110 litres. 


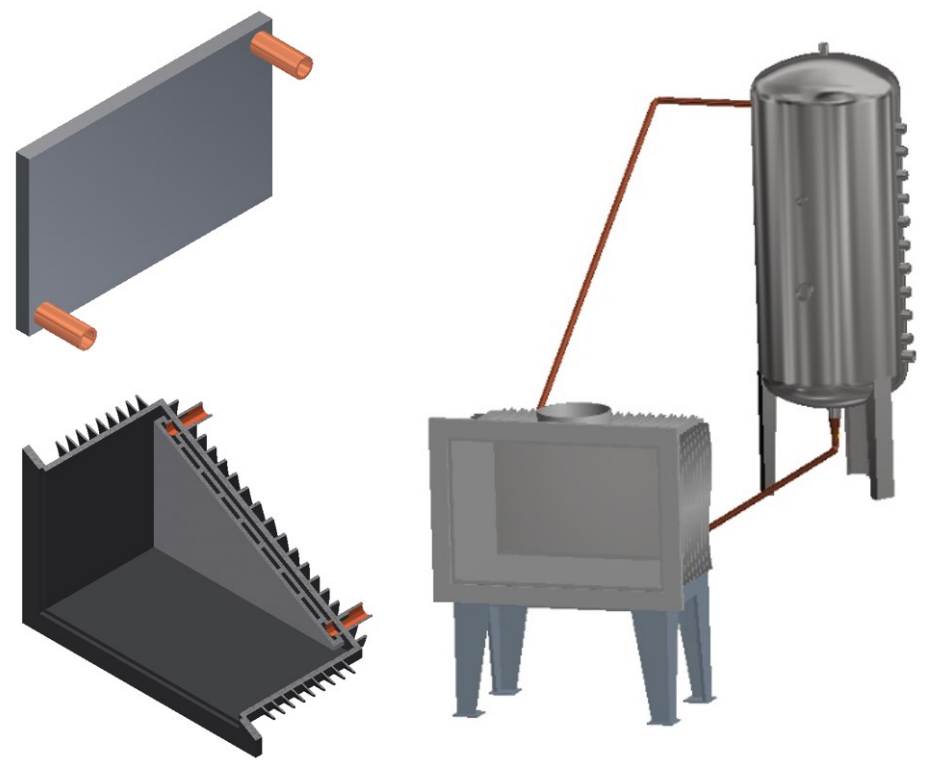

Fig. 4. Third variant of evaporator located in rear part of combustion.

In the production of the heat pipe, emphasis was placed on the suitability of the material with respect to the location of the individual parts of the device. Selection of the material has resulted in the selection of a suitable working substance to avoid chemical reactions between the material used and the working substance, which would lead to noncondensable gases and to reduce the efficiency of the thermal equipment (heat pipe).

From a design point of view, a second variant was chosen to extract the heat from the flue gases directly from the combustion chamber. The heat source is a double-shell of evaporator inserted in fireplace of heat performance $11 \mathrm{~kW}$.

The evaporator part of the heat pipe is located in the rear upper part of the combustion chamber. It is made of anti-corrosion material plate, AISI 306 steel, with a thickness of $4 \mathrm{~mm}$. The outside dimensions are $500 \times 200 \times 20 \mathrm{~mm}$. To prevent deformation of the evaporation part, which can be caused by pressure in the device, the inner space is reinforced with ribs. For the supply and removal of the working substance in the steam and liquid state, a steel pipe with diameter DN15 is located on the rear wall in the diagonal corners.

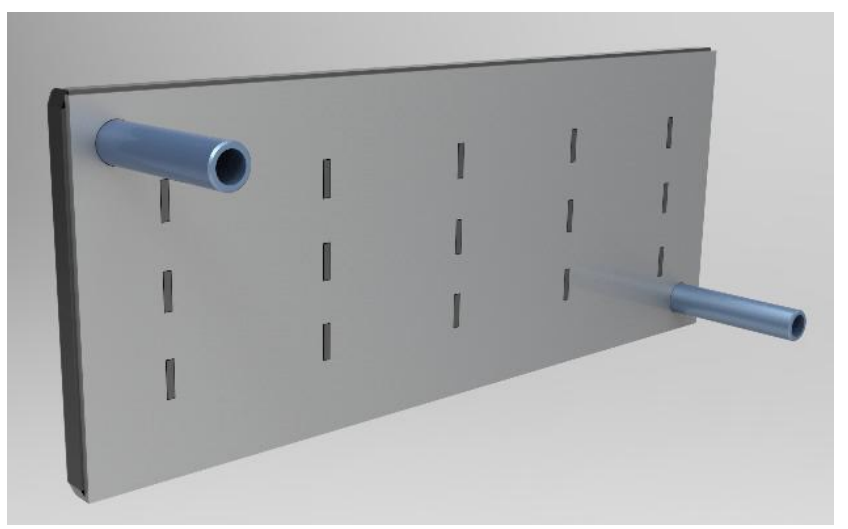

Fig. 5. Evaporator of heat pipe. 
The DHW cylinder, resp. The storage tank is located at the heat source due to the compactness and control of the individual parts of the heating device. The container is a staggered oval shape with a capacity of 110 litres. The storage tank is made of anticorrosion material AISI 304. The upper part of the container is a welded flange which serves to control and exchange the condensation part of the heat pipe, which is secured inside the container by means of a screw connection with a seal.

In the DHW cylinder or in the DHW cylinder. Of the storage vessel is a heat exchanger in the form of a threaded coil forming the condensing part of the heat pipe. The condensation part has been designed based on the water heating condition, which depends on the surface of the exchanger itself. For this reason, according to design, the largest possible area of the heat exchanger, resp. Condensing portion. The diameter of the spiral is $340 \mathrm{~mm}$, length $26 \mathrm{~m}$, pipe diameter $18 \mathrm{~mm}$, heat exchange area $1.45 \mathrm{~m}^{2}$ and volume 5.5 litres. The heat exchanger is made of copper, which is a very good heat conductor.
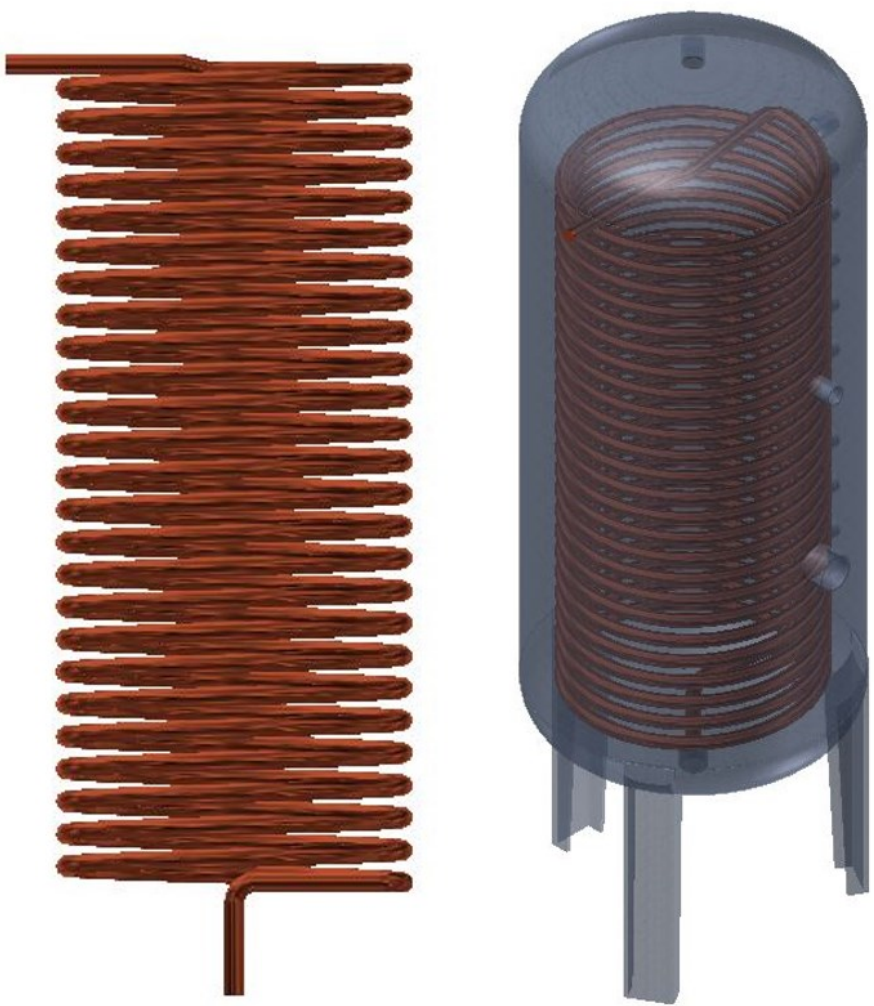

Fig. 6. Heat exchanger for hot water heating - condenser of heat pipe.

\section{Conclusion}

This article is an introduction to a series of exploration experiments using heat pipes for hot water heating. The next stage of the research will be designed and constructed experimental equipment. This device will be measured based on different requirements for different purposes. One of the objectives of the research will be to test the safety of the equipment for practical use and trouble-free operation of the equipment under all conditions. Hot water has become an integral part of our life. For its preparation, the technology in the area of heating and hot water production is being modernized and their design proposals help us to 
reduce the consumption of energy sources. Heat pipes can be used in the future to extract heat from the flue gas for heating or heating the water.

The research is supported by the European Structural Fund - project ITMS 26220220121 (50\%).

The research is supported by project "Limits of Radiative and Convective Cooling through the Phase Changes of Working Fluid in Loop Thermosyphon", APVV-15-0778 (50\%).

\section{References}

1. R. Nosek, S. Gavlas, R. Lenhard, M. Malcho, V. Sedlak, S. Teie, AIP conference proceedings, 1917, (2017)

2. P. Ďurčansky, Š. Papučík, J. Jandačka, M. Holubčík, R. Nosek, The scientific world journal 2014, (2014)

3. J. Jandačka, J. Mičieta, M. Holubčík, R. Nosek, Energy \& fuels. 31, 3 (2017)

4. R. Lenhard, K. Kaduchová, Š. Papučík, J. Jandačka, EPJ Web of Conferences 67, (2014)

5. P. Ďurčanský, M. Patsch, J. Jandačka, AIP conference proceedings, 1745. (2016)

6. P. Pilát, M. Patsch, Š. Papučík, M. Vantúch, AIP Conference Proceedings, 1608, (2014) 